\title{
Analisis Daya Dukung Pondasi Tiang Pancang pada Proyek Pembangunan Perhotelan/Apartemen/Kondominium di Jalan Ring Road Medan
}

\section{Analysis of Supporting Capacity of Piling Pile on Hospitality / Apartment / Condominium Development Project on Jalan Ring Road Medan}

\author{
Jesron Purba, Nuril Mahda Rangkuti*, Melloukey Ardan \\ Program StudiTeknik Sipil, FakultasTeknik, Universitas Medan Area, Indonesia \\ *Coresponding Email: nurilmahda@gmail.com
}

\begin{abstract}
Abstrak
Setiap bangunan sipil seperti gedung, jembatan, jalan raya, terowongan, menara, dan/tanggul dan sebagainya harus mempunyai pondasi yang dapat mendukungnya.Dalam pembangunan yang tanah dasar di bawah bangunan tersebut tidak mempunyai daya dukung (bearing capacity) yang cukup untuk memikul berat bangunan dan beban yang diterimanya atau apabila tanah pendukung yang mempunyai daya dukung yang cukup letaknya sangat dalam, maka biasanya memakai pondasi tiang. Pada umumnya pondasi tiang ditempatkan tegak lurus (vertikal) di dalam tanah, tetapi apabila diperlukan dapat dibuat miring agar dapat menahan gaya - gaya horizontal. Untuk mengetahui daya dukung tiang tersebut memenuhi Anda bisa memakai perhitungan daya dukung tiang statis.Daya dukung tiang metode statis yang berasal dari data SPT umumnya dipakai Luciano Dacourt dan Meyerhoff. Namun ini dapat kita bandingkan dengan hasil pengujian PDA test setelah tiang sudah dipancang minimal 14 hari. Apabila nilai daya dukung tiang berdasarkan data SPT lebih kecil dari hasil dari PDA test maka daya dukung tiang dalam pembangunan itu aman.
\end{abstract}

Kata Kunci: Analisis, Daya Dukung, Pondasi Tiang Pancang. Proyek Pembangunan.

\begin{abstract}
Every civil building such as buildings, bridges, highways, tunnels, towers, and / embankments and so on should have a foundation that can support it. In the development of the basic land under the building does not have sufficient bearing capacity to bear the weight of the building and the load it receives or if the supporting ground having sufficient carrying capacity is very deep, it usually uses a pile foundation. Generally the pile foundation is placed perpendicular (vertical) in the soil, but where necessary it can be tilted in order to withstand horizontal forces. To find out the carrying capacity of the pile it meets you can use the static pole bearing support calculation. The static data pile support method derived from SPT data is commonly used by Luciano Dacourt and Meyerhoff. But this we can compare with the results of PDA test test after the pole has been designed at least 14 days. If the value of bearing capacity of pole based on SPT data is smaller than the result of PDA test then the bearing capacity of pole in development is safe.
\end{abstract} Keywords: Analysis, Supporting Capacity, Pile Foundation. Project Development.

How to Cite: Purba, J. Rangkuti, M.N. Ardan. M. (2017). Analisis Daya Dukung Pondasi Tiang Pancang pada Proyek Pembangunan Perhotelan/Apartemen/Kondominium di Jalan Ring Road Medan. JCEBT (Journal of Civil Engineering, Building and Transportation). 1 (1): 19-26. 


\section{PENDAHULUAN}

Pondasi sangat penting dalam suatu pekerjaan teknik sipil dalam hal ini pekerjaan suatu struktur bangunan. Bentuk dan struktur tanah juga berperan dalam suatu pekerjaan konstruksi untuk menentukan jenis pondasi tersebut, hal ini disebabkan karena kondisi ketidak tentuan dari struktur tanah itu sendiri. Sebelum melaksanakan suatu pembangunan konstruksi yang pertama-tama dilaksanakan dilapangan dan dikerjakan di lapangan adalah pekerjaan pondasi (struktur bawah). Dalam sebuaah kesatuan bangunan yang utuh pondasi adalah merupakan struktur yang berfungsi untuk menahan/memikul beban bangunan sekaligus menopang bangunan yang ada diatasnya (konstruksi atas) yang kemudian beban tersebut akan diteruskan ke tanah. Pondasi ini akan menyalurkan tegangantegangan yang terjadi pada sturuktur atas kedalam lapisan tanah yang keras yang dapat memikul beban konstruksi tersebut.

Pondasi sebagai struktur bawah secara umum dapat dibagi kedalam dua jenis yaitu pondasi dangkal dan pondasi dalam.Pemilihan jenis pondasi tergantung kepada jenis struktur atas apakah termasuk pada konstruksi beban ringan atau beban berat dan juga tergantung kepada jenis tanahnya.Untuk konstruksi beban ringan dan kondisi tanah cukup baik, biasanya dipakai pondasi dangkal, tetapi untuk konstruksi beban berat, biasanya dipakai pondasi dalam.

Secara umum permasalahan pondasi dalam lebih rumit dari pondasi dangkal.Untuk hal itu, penulis mencoba mengkonsentrasikan Tugas Akhir ini pada perhitungan daya dukung tiang pancang berdasarkan data SPT dan perbandingannya dengan hasil pengujian PDA. Pondasi tiang pancang adalah batang yang relatif panjang dan langsing yang digunakan untuk menyalurkan beban pondasi melewati lapisan tanah dengan daya dukung rendah kelapisan tanah yang keras yang mempunyai daya dukung yang tinggi yang dianggap cukup dalam dibandingkan pondasi dangkal. Daya dukung tiang pancang diperoleh dari daya dukung ujung (end bearing capacity) yang diperoleh dari tekanan ujung tiang dan daya dukung geser atau selimut (friction bearing capaity) yang diperoleh dari daya dukung gesek antara tiang pancang dan tanah disekelilingnya.

Tiang pancang berinteraksi dengan tanah untuk menghasilkan daya dukung yang mampu memikul dan menahan beban stuktur atas. Untuk menghasilkan daya dukung yang akurat maka diperlukan suatu penyelidikan tanah yang akurat juga. Ada dua metode yang biasa digunakan dalam penentuan daya dukung tiang 
pancang yaitu metode statis dan metode dinamis.

Penyelidikan tanah dengan menggunakan metode statis adalah penyelidikan Sondir dan Standart Penetrasi Test (SPT) .Penyelidikan sondir bertujuan untuk mengetahui perlawanan penetrasi konus dan hambatan lekat tanah yang merupakan indikasi dari kekuatan daya dukung lapisan tanah dengan rumus empiris. Penyelidikan standart penetrasi test (SPT) bertujuan untuk mendapatkan gambaran lapisan tanah berdasarkan jenis dan warna tanah melalui pengamatan secara visual dan karakteristik tanah. Data standart penetrasi test (SPT) dapat digunakan untuk menghitung daya dukung.

Maksud dan tujuan penelitian ini adalah untuk menghitung daya dukung pondasi tiang pancang dengan menggunakan data SPT (Standard Penetration Test) dan bertujuan untuk membandingakan hasil daya dukung pondasi tiang pancang berdasarkan hasil pengujian PDA (Pile Driving Analize).

Jenis pondasi tiang pancang yang sesuai terhadap struktur tanah dan daya dukung tanah. Pengambilan data mengenai daya dukung tanah melalui sistim sondir. Menghitung daya dukung pondasi tiang pancang melalui data SPT (Standard Penetration Test). Membandingkan hasil perhitungan daya dukung tiang pancang dengan hasil pengujian PDA (Pile Driving Analize). Sistem pelaksanaan pekerjaan pondasi tiang pancang yang diselaraskan terhadap efesiensi waktu pelaksanaan pekerjaan tersebut. Analisa biaya pelaksanaa pekerjaan tersebut.

\section{METODE PENELITIAN}

Dalam penyusunan laporan ini, penulis melakukan beberapa metode dalam mengumpulkan data yang mendukung laporan ini. Adapun metode tersebut antara lain sebagai berikut. Melakukan pengamatan langsung ke lapangan. Studi kepustakaan (literatur). Meminta data kepada pihak owner (pemilik), seperti data SPT, PDA dan datadata lainnya. Konsultasi dengan dosen pembimbing. Melakukan tanya jawab dan konsultasi dengan pihak owner (pemilik). Pengambilan gambar di lapangan.

Adapun teknik pengolahan data yang dilakukan penulis antara lain: Menghitung daya dukung pondasi tiang pancang tunggal berdasarkan data SPT menggunakan rumus Meyerhof dan Luciano Decourt. Menyusun bagian laporan tugas akhir suai dengan tugas akhir.

Pondasi dapat didefenisikan sebagai bangunan bawah dan tanah dan/atau batuan disekitarnya yang akan 
dipengaruhi oleh elemen bangunan bawah dan bebannya (Bowles, 1986). Pondasi tiang adalah suatu konstruksi pondasi yang mampu menahan gaya orthogonal ke sumbu tiang dengan cara menyerap lenturan. Pondasi tiang dibuat menjadi suatu kesatuan yang monolit dengan menyatukan pangkal tiang pancang yang terdapat dibawah konstruksi, dengan tumpuan pondasi (Sosrodarsono, 1980).

Secara umum pondasi tiang mempunyai ketentuan-ketentuan:

1. Mampu meneruskan gaya-gaya vertikal yang bekerja padanya untuk diteruskan kelapisan tanah pendukung (bearing layers).

2. Dengan adanya hubungan antara kepala-kepala tiang satu dengan lainya mampu menahan perubahanperubahan bentuk tertentu kearah mendatar (tegak lurus terhadap as tiang).

3. Apabila kita perhatikan ketentuanketentuan tersebut di atas, maka tidak perlu bahwa tiang pancang harus terletak di bawah tanah dan selalu dihubungkan dengan poer. Pondasi tiang yang tidak berhibungan langsung dengan poer tetapi berhubungan langsung dengan balok-balok melintang pada bangunan atas dapat pula diperlakukan sebagai pondasi tiang.
4. Jika diameter tiang menjadi lebih besar atau tiang menjadi lebih pendek sehingga kekakuannya bertambah besar, maka tiang tersebut merupakan tiang pendek atau sort pile yang mempunyai ketentuan-ketentuan lain daripada tiang pancang atau long pile didalam perhitungannya (Sarjono Hs, 1991).

Tanah mempunyai peran yang sangat penting pada suatu lokasi perkerjaan konstruksi. Tanah adalah pondasi pendukung suatu bangunan, atau bahan konstruksi dari bangunan itu sendiri seperti tanggul atau bendungan, atau kadang-kadang sumber penyebab gayaluar suatu bangunan, seperti tembk/dinding penahan tanah (Sosrodarsono, 1980).

Tiang pancang adalah bagian-bagian konstruksi yang dibuat dari kayu, beton, dan/atau baja, yang digunakan untuk mentransmisikan beban-beban permukaan ketingkat-tingkat permukaan yang lebih rendah dalam massa tanah. Hal seperti ini ialah mengenai tiang-pancang yang ditanamkan sebagian yang terpengaruh baik oleh beban vertikal dan tekuk, maupun beban lateral (Bowles, jilid 2).

Percobaan ini adalah suatu percobaan dinamis, alatnya yang dinamakan "Spilt spoon sample " dimasukkan kesalam tanah pada dasar 
lubang bor dengan memakai suatu beban penumbuk yang seberat 140 pound (63 kg) yang dijatuhkan dari ketinggian 30 inchi $(76,2 \mathrm{~cm})$. Setelah "Spilt spoon ini dimasukkan 6 inchi $(15,2 \mathrm{~cm})$, jumlah pukulan dihitungkan untuk memasukkan 1 foot (12 inchi ataau $30,48 \mathrm{~cm}$ ) berikutnya. Jumlah pukulan ini desebut $\mathrm{N}$ dengan satuan pukulan/kaki.

Niali "N" yang diperoleh dengan percobaan SPT dapat dihubungkan secara empiris dengan beberapa sifat lain dari pada tanah yang bersangkutan.

Untuk nilai "N" pada lapisan pasir halus dan pasir kelanauan dengan ukuran butir 0,1-0,05 mm dipengaruhi permukaan air tanah, jadi perlu dikoreksi.

$\mathrm{N}=15+1 / 2\left(\mathrm{~N}^{\prime}-15\right)$

\section{Dimana :}

$\mathrm{N}$ = nilai SPT setelah dikoreksi

$\mathrm{N}^{\prime}$ = nilai SPT yang diukur dengan catatan percobaan, N'>15

Pada lapisan tanah tidak berkohesi (pasir\& lanau), harga $\mathrm{N}$ dapat dihubungkan dengan kepadatan relatif dan sudut geser.

Harga kohesi dan sudut geser dalam tanah ( c dan $\emptyset$ ) tergantung pada macam dan sifat bahan timbunan, sebaiknya c dan $\emptyset$ ditentukan bersasarkan hasil laboratorium.

\section{Daya Dukung Dari SPT}

SPT banyak sekali digunakan untuk mendapatkan daya dukung tanah secara langsung.Salah satu hubungan yang pertama dikemukakan adalah rumus Meyerhof dan Luciano Decourt.Rumus ini telah dipakai secara meluas.Meyerhof mengemukakan persamaan untuk menghitung daya dukung ijin untuk penurunan sebesar $25 \mathrm{~mm}$.

\section{Metode Meyerhoff}

Salah satu cara untuk menghitung daya dukung tiang dapat dipakai rumus Meyerhof yang dimodifikasi oleh A.I.J. (Architectural Institute of Japan). (Sardjono, Pondasi Tiang Pancang Jilid II, hal 39)

$\mathrm{R}=\mathrm{Rt}+\mathrm{RS}$

$\mathrm{R}$ ijin $=\mathrm{Rt} / 3+\mathrm{Rs} / 5$

Rt $=\mathrm{m} \times \mathrm{N} \times \mathrm{At}$

Rs $\quad=n \times \operatorname{Nr} \times$ As $x$ D ...( II. 5)

$\mathrm{m}=$ = koefisien perlawanan ujung.

$\mathrm{n}=$ koefisien perlawanan gesek tiang

$\mathrm{N}=$ nilai $\mathrm{N}-\mathrm{SPT}$ pada ujung tiang

$\mathrm{Nr} \quad=$ nilai $\mathrm{N}$-SPT rata-rata sepanjang kedalaman tiang yang ditinjau At = luas penampang tiang

AS = luas selimut pada kedalaman yang ditinjua

D = kedalaman tiang pancang yang ditinjau 


\section{HASIL DAN PEMBAHASAN}

Metode Meyerhoff

Dari persamaan II.5 metode yang dikemukakan oleh Meyerhof (1976)

$$
\begin{array}{ll}
\mathrm{R} & =\mathrm{Rt}+\mathrm{Rs} \\
\mathrm{Rijin} & =\mathrm{Rt} / 3+\mathrm{Rs} / 5 \\
\mathrm{Rt} & =\mathrm{m} \times \mathrm{N} \times \mathrm{At} \\
\mathrm{Rs} & =\mathrm{n} \times \mathrm{Nr} \times \text { As } \times \mathrm{D} \\
\mathrm{Nr} & =42
\end{array}
$$

Keliling tiang (As) $=\pi \mathrm{xd}$

$$
\begin{aligned}
& =\pi \times 40 \mathrm{~cm} \\
& =1,257 \mathrm{~m}
\end{aligned}
$$

Luas penampang $(\mathrm{At})=1 / 4 \pi \mathrm{xd} 2$

$$
\begin{aligned}
& =1 / 4 \pi \times 252 \\
& =0,126 \mathrm{~m} 2
\end{aligned}
$$

Dari persamaan (II.5), daya dukung

$$
\begin{array}{ll}
\text { batas tiang (R): } \\
\mathrm{R} \quad=\mathrm{Rt}+\mathrm{Rs} \\
\mathrm{Rijin} \quad=\mathrm{Rt} / 3+\mathrm{Rs} / 5 \\
\mathrm{Rt} \quad=\mathrm{m} \times \mathrm{N} \times \mathrm{At} \\
\mathrm{Rs} \quad=\mathrm{n} \times \mathrm{Nr} \times \text { As } \times \mathrm{D} \\
\mathrm{Rt} \quad=40 \text { ton } / \mathrm{m} 2 \times 42 \times 0,126 \mathrm{~m} 2 \\
\quad=211,68 \text { ton } \\
\mathrm{Rs} \quad=0,2 \text { ton } / \mathrm{m} 2 \times 38 \times 1,257 \mathrm{~m} \times 2,00 \mathrm{~m} \\
\quad=128,724 \text { ton }(19,1064 \text { ton }) \\
\mathrm{R} \quad=19,1064 \text { ton }+211,68 \text { ton } \\
= & 230,7864 \text { ton }
\end{array}
$$

Rijin $=327,280 / 3+128,724 / 5$

Rijin $=109,09$ ton $+25,74$ ton

Rijin $=134,83$ ton.

\section{Metode Luciano Dacourt}

$\mathrm{Qu}=\mathrm{QP}+\mathrm{QS}=(\mathrm{qP} \cdot \mathrm{AP})+(\mathrm{qS} \cdot \mathrm{AS})$

$$
\begin{aligned}
& =(\mathrm{NP} \cdot \mathrm{K} \cdot \mathrm{AP})+[(\mathrm{NS} / 3+1) \cdot \mathrm{AS}] \\
\mathrm{Q}(\mathrm{ijin}) & =\mathrm{Qu} / \mathrm{sf}
\end{aligned}
$$

dengan :

$\mathrm{NP}=$ harga rata-rata SPT di sekitar 4B di atas hingga 4B dibawah dasar tiang pondasi.

$\mathrm{B}=$ Diameter pondasi $=700 \mathrm{~mm}$

$\mathrm{K}=$ koefisien karakteristik tanah untuk :
a. Lempung, $\mathrm{K}=12 \mathrm{t} / \mathrm{m} 2$
b. Lanau berlempung, $K=20 \mathrm{t} / \mathrm{m} 2$
c. Lanau berpasir, $\mathrm{K}=25 \mathrm{t} / \mathrm{m} 2$
d. Pasir, $\mathrm{K}=40 \mathrm{t} / \mathrm{m} 2$

$\mathrm{AP}=$ luas penampang dasar tiang (m2)

NS = harga rata-rata SPT sepanjang tiang yang tertanam (D), dengan batasan $3 \leq \mathrm{N} \leq$ 50 .

AS = luas selimut tertanam $=$ keliling $\mathrm{x}$ panjang tiang yang terbenam (m2)

Sf = safety factor, diambil 3 .

Melalui data Boring Log dan SPT BH3 yang ditinjau pada kedalaman 19 m kita dapat menghitung daya dukung tanah tersebut, dengan cara :

a) Menghitung NP

Nilai rata-rata SPT di sekitar 4B di atas dan 4B di bawah dasar tiang pondasi adalah Np. Nilai SPT yang dirata-ratakan adalah nilai SPT yang telah di design dengan persamaan $\mathrm{N} 1=15+0,5(42-15)=28,5$ SPT; dst (Data SPT BH-3)

Jadi, $N P=(28,5+38=16,625$ SPT $;$ dst 
b) Menghitung qP

Tegangan ultimate ujung tiang (qp). Di mana qp bisa didapat dengan mengalikan nilai Np dan $\mathrm{K}$, di mana $\mathrm{K}$ adalah koefisien karakteristik tanah. Karena karateristik tanah yang didapat lempung maka nilai $\mathrm{K}=12 \mathrm{t} / \mathrm{m} 2$ Jadi qP = 16,625 x $12=199,5$ t/m2; dst.

\section{c) Menghitung Ap}

Luas penampang dasar tiang (Ap). Penampang tiang berbentuk lingkaran. Jadi $A p=1 / 4 \times 3,14 \times B 2=0,385 \mathrm{~m} 2$.

d) Menghitung Qp

Daya dukung ujung tiang (Qp). Ini bisa didapat dengan cara mengalikan qp dengan Ap, seperti :

$\mathrm{Qp}=\mathrm{qp} \times \mathrm{Ap}=199,5+0,385=76,8075$ ton.

\section{e) Menghitung NS}

Harga rata-rata sepanjang tiang yang tertanam dengan batasan $3 \leq \mathrm{N} \leq 50$. Adalah Ns.

\section{f) Menghitung As}

Luas permukaan tiang atau luas selimut tertanam, adalah As = keliling $\mathrm{x}$ panjang tiang yang terbenam (m2).

Didapat As $=3,14 \times 700 \times 19=41,762 \mathrm{~m} 2$

\section{g) Menghitung Qs}

Daya dukung akibat gesekan tiang adalah Qs. Ini dapat dihitung dengan cara $\mathrm{Qs}=(\mathrm{Ns} / 3+1) \times$ As. Didapat di titik BH-3 adalah :

$Q s=(38 / 3+1) \times 41,762=570,747$ ton.

h) Menghitung Qu

Daya dukung tanah maksimum $(\mathrm{Qu})$. Di mana $\mathrm{Qu}=(\mathrm{QP}+\mathrm{QS})$. Jadi, $\mathrm{Qu}=$ $(570,747+76,807)=645,554$ ton.

$\mathrm{Qu}(\mathrm{ijin})=\mathrm{Qu} / \mathrm{sf}=645,554 / 3=215,85$ ton.

Perhitungan kapasitas daya dukung untuk titik BH-1 BH-3, BH-4, BH-6 pada kedalaman lainnya dan diameter rencana $(40,50,60,70) \mathrm{cm}$ dapat dilihat pada tabel-tabel berikut ini:

\section{Hasil Pengujian Lapangan Test PDA}

Pengujian test PDA dilakukan pada tiang pancang dengan nomor PC1-40, PC150, PC1-60, PC1-70 dengan masing-masing diameter yang berbeda yaitu diameter 400, 500, 600, $700 \mathrm{~mm}$ sebanyak 4 (empat) titik di jalan Ring Road Medan dengan kedalaman yang sama yaitu $19 \mathrm{~m}$. Karakteristik hammer yang digunakan dalam pengujian ini adalah DIESEL HAMMER dengan berat 1,6 ton dengan tinggi jatuh 2,1 m. 


\section{SIMPULAN}

Dari hasil perhitungan maka dapat disimpulkan bahwa kapasitas daya dukung tiang pancang pada proyek pembangunan apartemen/perhotelan/kondominium berdasarkan metode Meyerhoff berada disekitar 147,982 s/d 390,145 ton, dan untuk metode Luciano Decourt antara 481,808 s/d 841,190 ton. Perbandingan antara hasil perhitungan berdasarkan data SPT ini dengan data PDA tes dengan metode Meyerhoff adalah sebesar 55,75 \%, sedangkan untuk metode Luciano Decourt adalah sebesar 31,51\%.

\section{DAFTAR PUSTAKA}

Asroni, A. Kolom Pondasi Dan Balok T Beton Bertulang “.

Bowles, J. (1986). Analisis Dan Disain Pondasi Tiang Pancang ", Jilid 1 Edisi Ke Empat, Penerbit Erlangga - Jakarta.

Bowles, J. (1986). Analisis Dan Disain Pondasi Tiang Pancang, Edisi Ke Empat Jilid 2, Penerbit Erlangga - Jakarta.

Das Braja, M. (1995). Mekanika Tanah (PrinsipPrinsip Rekayasa Geoteknis). Jilid 1, Penerbit Erlangga (Anggota IKAPI) - Jakarta.

Sardjono. (1988), Pondasi Tiang Pancang “, Edisi Pertama, Penerbit Sinar Wijaya - Surabaya.

Sardjono. (1991). Pondasi Tiang Pancang Jilid II", Penerbit Sinar Wijaya - Surabaya.

Gunawan, R. (1983), Teknik Pengantar Pondasi. Penerbit Kanisius (Anggota IKAPI) Yokyakarta.

Sunggono, V. (1995), Buku Teknik Sipil. Penrbit Nova - Bandung.

Simatupang, T.P. Rekayas Pondaasi II.

Sorsodarsono, S. (1980), Mekanika Tanah Dan Teknik Pondasi, Penerbit PT. Pradnya Paramita - Jakarta. 